\title{
ÉTICA E ESTTÉTICA: O DESTINO DO LITORAL
}

PAULO RENATO MESQUITA PELLEGRINO E SILVIO SOARES MACEDO

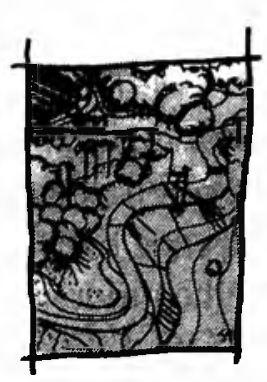

Colaboradores: Belmiro dos Santos Rodrigues Neto e Mauro Font

\section{A ARQUITETURA DA PAISAGEM EM BUSCA DE RESPOSTAS CONCRETAS}

Acompanhandooadvento do movimento ambiental houve um aumento de preocupação e interesse com a estética da paisagem. Considerações a respeito das qualidades cênicas em planos de manejo territorial, de impactos visuais, resultantes de grandes obras passaram a ser correntes.

Mas este desejo de desenvolver formas de avaliação e intervenção na paisagem carregam ainda uma ênfase meramente visual muito forte, denotando as origens da estética da paisagem que encontra suas fontes na arte e literatura européias dos sécs. XVII, XVIII e XIX; como expressam as obras de um Lorrain, Watteau de Constable, que invocam imagens romanceadas de uma natureza idealizada. Esta visão tornou-se o paradigma da valoração das paisagens e o modelo dos parques urbanos e subúrbios residenciais até os dias de hoje.

Com a brutal evolução havida nas ciências ambientais, no conhecimentos dos elementos e no funcionamento da complexa e frágil rede de fenômenos que dão as condições de existência da vida neste planeta; houve uma ampliação da percepção ambiental e a própria estética da paisagem passou a responder necessariamente a uma mais holística ecologia da paisagem.

Surge então a imposição de que as apreciações das paisagens naturais e culturais sejam condizentes a uma ética ambiental, a um uso racional e sustentado do conjunto dos recursos que garantem a estabilidade e produtividade dos ecossistemas afetados. Da procura de princípios, métodos e técnicas para modelar a paisagem, o uso do solo e os recursos naturais, de modo que os ecossistemas humanos possam funcionar à maneira sustentada dos ecossistemas naturais, e que sirvam aos interesses do homem e da natureza.

\section{LITORAL/PAISAGEM E PADRÕES DA OCUPAÇÃO}

A costabrasileira, como todo o territórionacional, sofre neste final de século um intenso processo de ocupação antrópica, de uma destruição radical de seus recursos ambientais, de uma exploração máxima de seus valores cênicos e está, já, em muitos e importantes de seus segmentos se configurando numa grande avenida beira-mar, que em um futuro, talvez não tão próximo, vai estar percorrendo toda sua extensão de norte a sul do país. 
Ela na realidade já existe e ocupa trechos significativos do Rio Grande do Norte. São Paulo, Alagoas, Pernambuco. Santa Calarina, Espírito Santo, Rio de Janeiro, etc. e por todo o ano, em especial nos meses de férias, milhões de pessoas sĩo atraídas a centros de turismo $\mathrm{cm}$ busca de sol $\mathrm{c}$ mar. Duas formas radicais de ocupação s̃̃o aceitas, a primeira, aquela da praia bordcjada de pistas de asfalto, com barracas de comida, prédios altos e casas seguindo o modelo consagrado pelas praias do Rio de Janeiro e Santos e em outro extremo a praia dila "deserta", Iocal idílico, éden, onde sob coquciros e em meio a um mar azul c arcias alvas sc tem para uns poucos conhecedores do lugar um simulacro do paraíso. A cada ano algumas praiass são ancxadas ao rol c rotciro das praias idílicase pouco a pouco como a famosa Canoa Quchada. 1 endem a ser anexadas ao rotciro de muitos milhares de turistas, são loteadas, o asfalto chega c o vello modelo de ocupação das praias do sol se repete.

Por outro lado, outras tantas partes da costa vão sendo ocupadas por instalações industriais de porte, terminais marítimos, elc. c vão tendo sua morfologia destruída e muilos de seus recursos consumidos, enquanto as águas sc tomaun inadequadas para pescal ou banhos (como ć o casoso extremo da baúi de Guanabarà, em grande parte de sua extensĩo).

Cada vez mais, à medida que as pressões da socicdade aumentam, no sentido de se agilizar a ocupação do país. o litoral deve ser considerado cm toda a plenitude do seu potencial c não do ponto de vista luncional, utilitário, de lazzer ou cênico. Ao longo de toda a costa. caracterizada a cada segmento por uma morfologia lípica, abrigando ccossistemas importantes - dunas, malas, mangues, costóes, restingas, hancos de coral, elc. se tem o habitat natural para formas de vida das mais diversas, tanto animais como vegelais e estas de muilo servem ou poderĩo servir às comunidades humanas.

Os recursos existentes são incontáveis, lanto a nível da produção de alimentos, como para a indústria de processimento de algas, para o lurismo elc. eestessão linitos. Finitos e muito poucas vezes renováveis com facilidade. A recuperação possível só se dará a partir de um alto investimento e em um tempo de malturação signilicativo. o que pode e causa sempre transtornos à sociedade.

O processo de produção do espaço cosıciro está se colocando em dúvida, pelas próprias contradições da sua organização. Cada novo loteamento construído tende a reproduzir na praia o ideário pelo menos do subúrbio urbano com suas casinhas isoladas ou $\mathrm{cm}$ outros pontos, de alto valor, constiluem situações de alta densidade de construçĩo verticalizadas, tais quais bairros densos de cidades do interior do país. Se vai à praia para sair da cidade c suas formas de organizaçãoespacial, c se cai cm sua réplicaà beirn-mar.

Não ocupar o litoral ć um absurdo, mas ccrtamente ć um contra-scnso às formas de ocupação vigentes. As próprias soluções paleativas existentes à criação de uns poucos 
parquesnacionais sāopontuaise efetivamente têm pouco raiode alcançe eoutras formas de planejamento deste ambiente devem ser implementadas e algumas já estão em processo de efetivação.

Deve-se então avaliar cada lugar na costa pelos seus valores cênicos e ambientais, pela disponibilidade de recursos existentes, suas possibilidades de esgotamento, reposição e transformação e se encaminhar para uma definição mais clara de formas de ocupação, mais ou menos intensas na medida que se possam ter csta ou aquela forma de reposição ou convivência com o recurso. scja cle desde uma paisagem "bonita" até um mangueberçário animal e não tão bonito aos olhos do usuário/turista lípico.

\section{ESTUDO DE CASO: ILHA COMPRIDA}

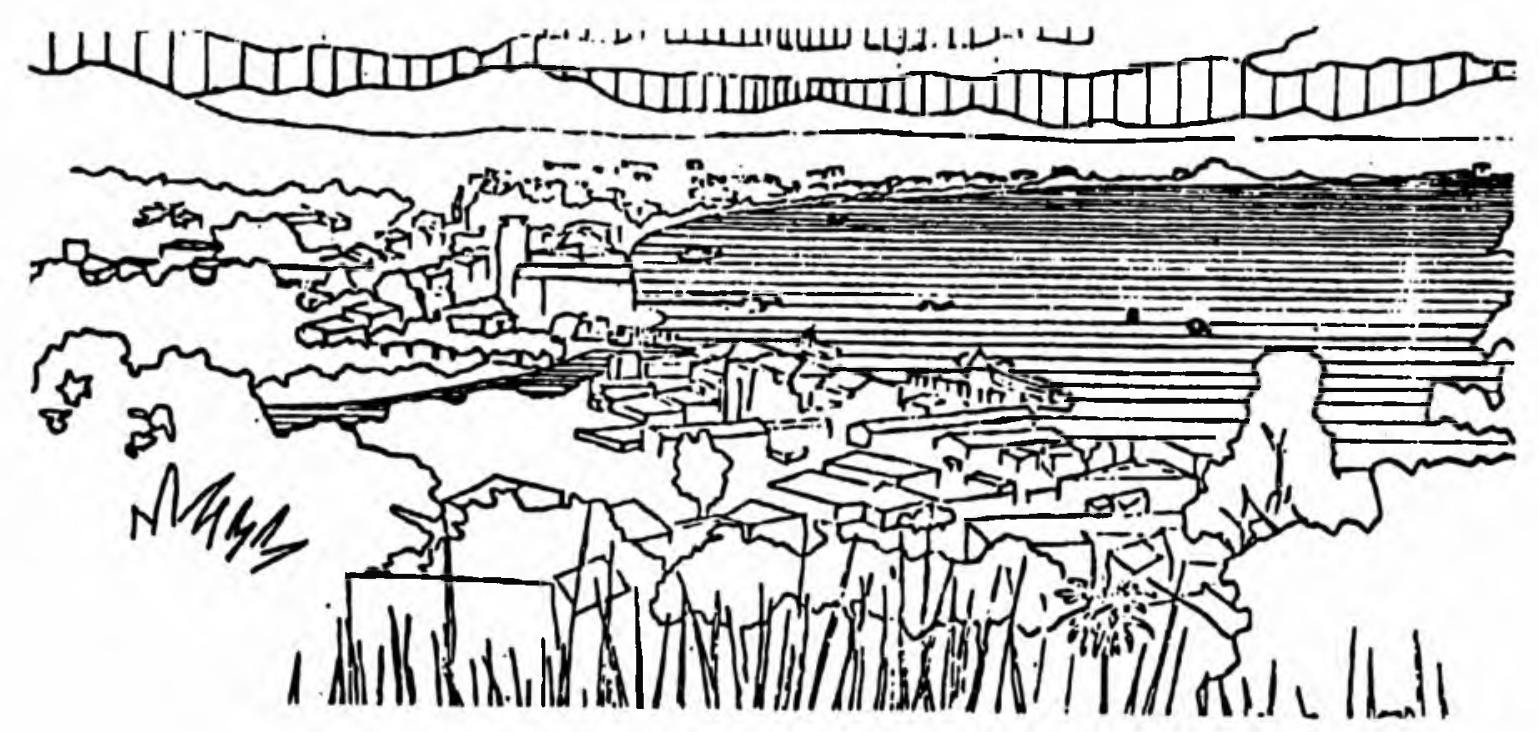

Localiza-se no litoral sul do estado de São Paulo, em um complexo conhecido como Região Lagunar - Estuarina do Iguape e Cananéia, considerndo como o quinto maior de importância lagunar do mundo. A ilha de $70 \mathrm{~km}$ de ex lensĩo por uma largura média de $3 \mathrm{~km}$ contém extensas praias, importintes segmentos tlorestados c de mangucs. dunas c uma urbanização predatória cjuc obedece estritamente aos padrōes maịs destrutivos dos recursos ambientais existentes (aproximadamente 220.000 lotes distribuídos em quase 200 lotcamentos). A illa cercada por inúmeras áreas de rescrva é considerada uma APA - Área de Proleção Ambiental c somente agora passa a ser objeto de propostas oficiais efetivas (Fig. 1).

A partir do cruzamento de um conjunto de informações básicas obtidas na Secretaria do Meio Ambiente/SP. do material cartográlico disponível SEMA/IBGE/lGC e de estudo bibliográlico pertinente e da avaliação in loco das potencialidades paisagísticas 
da ilha foram elaboradas pranchas temáticas representando o sistema natural em seus elementos bióticoseabióticos, o uso dos solos mostrandosuas intensidades e tendências de expansãoe uma compreensão do sistemaecológicoe sócioeconômico do lugar, como resultado final obtiveram pranchas-sínteses de compatibilidades para uso humanoe dos ecossistemas existentes (Fig. 2).

Três foram as propostas de configuração paisagística básica resultantes deste processo.

1. De ocupação linear da praia e preservação drástica do interior da ilha, mostrando um confronto direto entre a visão do idílico, do "éden" e da ocupação urbana tradicional (Fig. 3).

2. Setorização total do espaço da ilha, com definições morfológicas e funcionais de acordo com o meio existente. Limitação da urbanização e estabelecimento de níveis de controle, mas ainda carregada com uma grande ênfase a visão "verde/nalural”(Fig.4).

3. Ocupação urbana distribuída eqüitativamente por todo o espaço, criando-se uma hierarquia de ocupação de acordo com a maior ou menor sobreposição desejada da urbanização sobre os ecossistemas existentes, permitindo uma ocupação mais intensa, conservando os recursos disponíveis, atendendo a demanda de lazer/recreação e respondendo concretamente aos objetivos principais do exercício, mas não entrando ainda em um detalhamento preciso do projeto (Fig. 5).

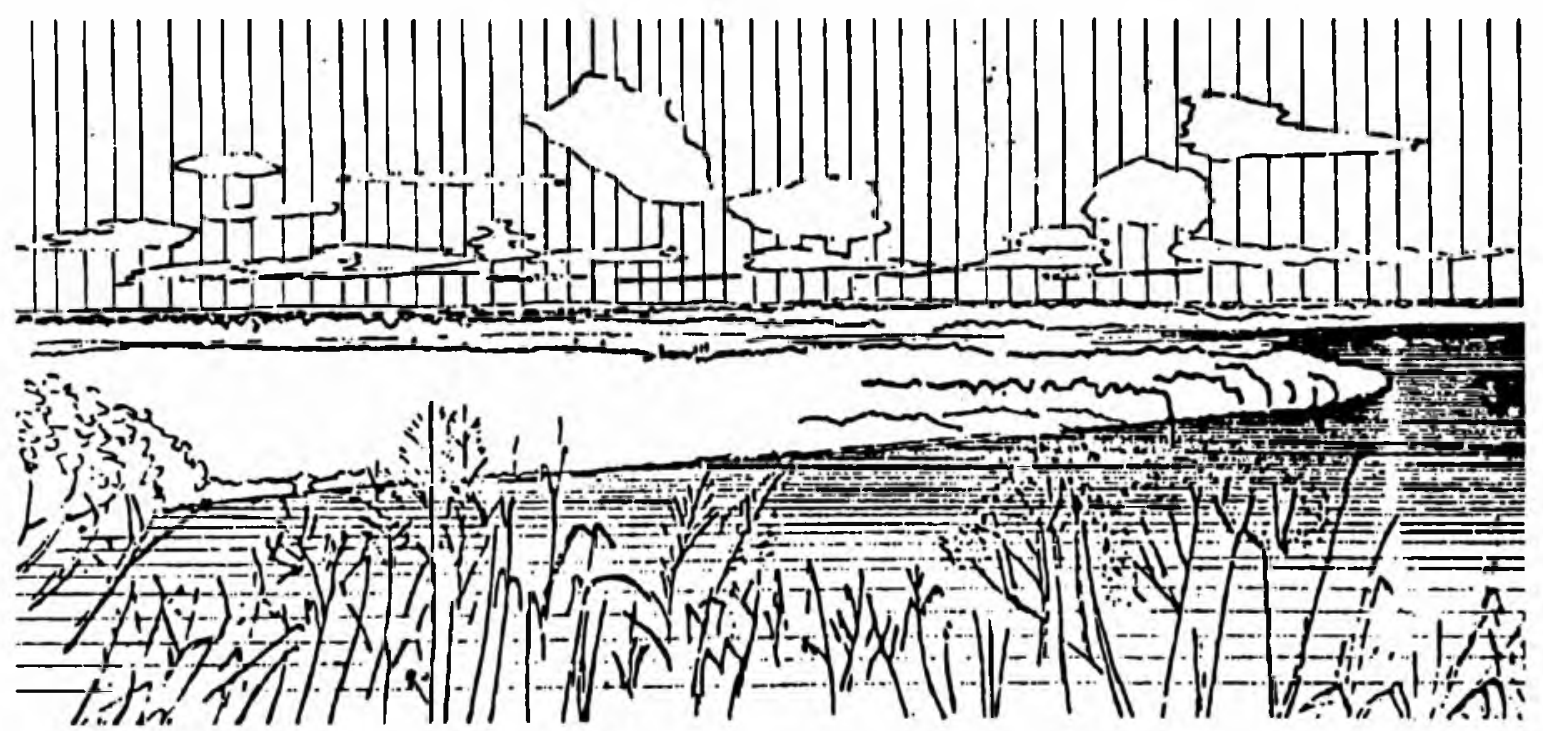




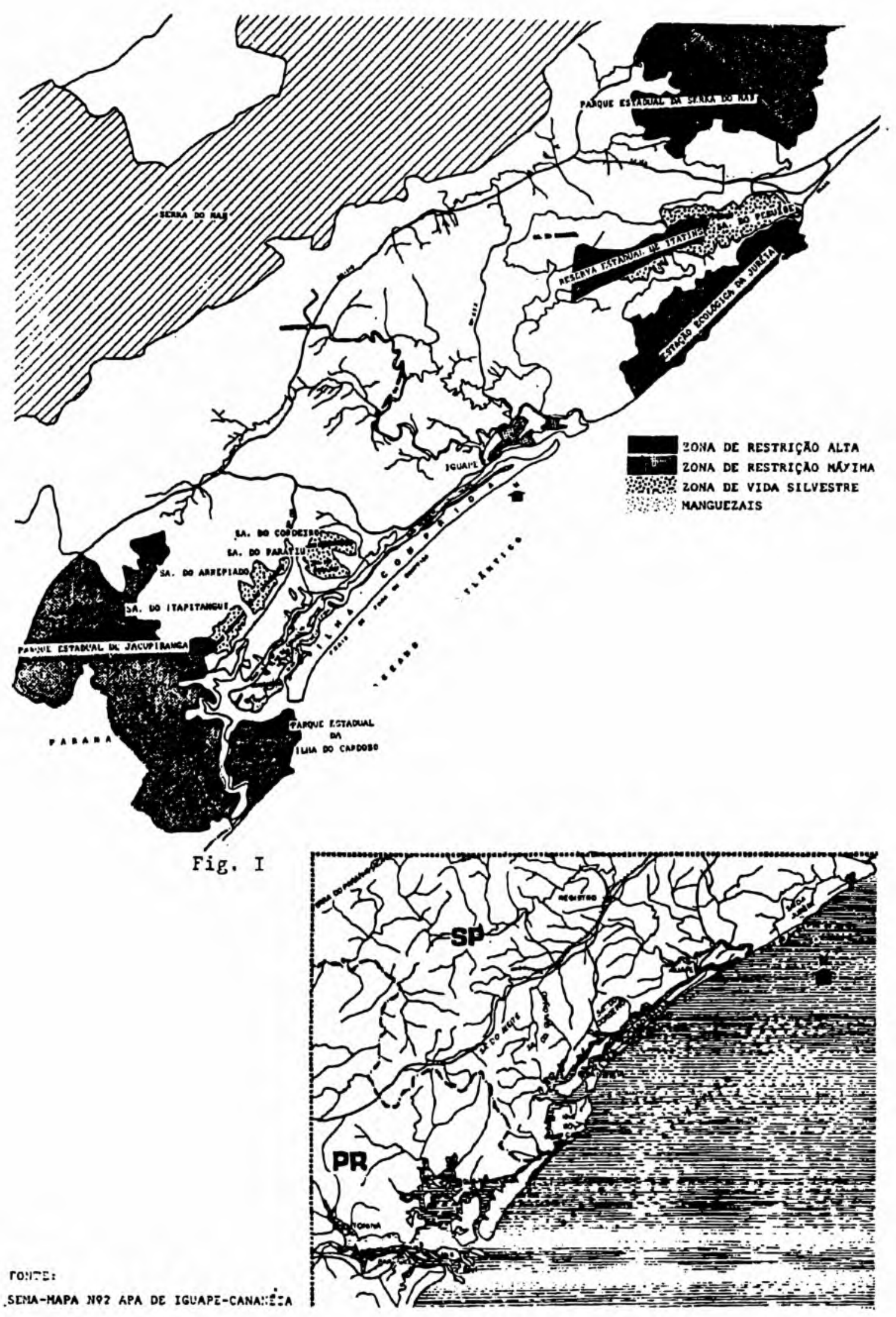



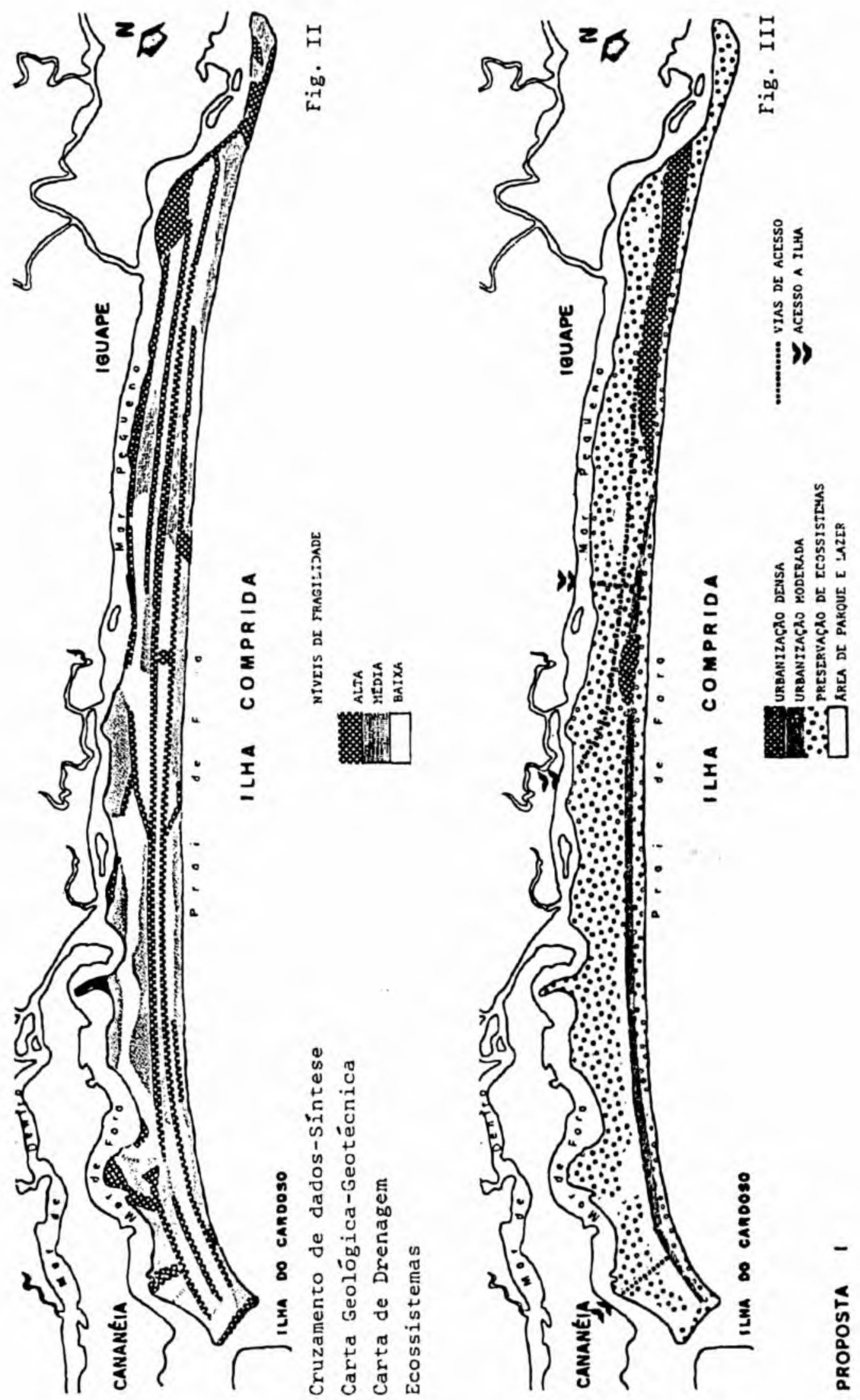

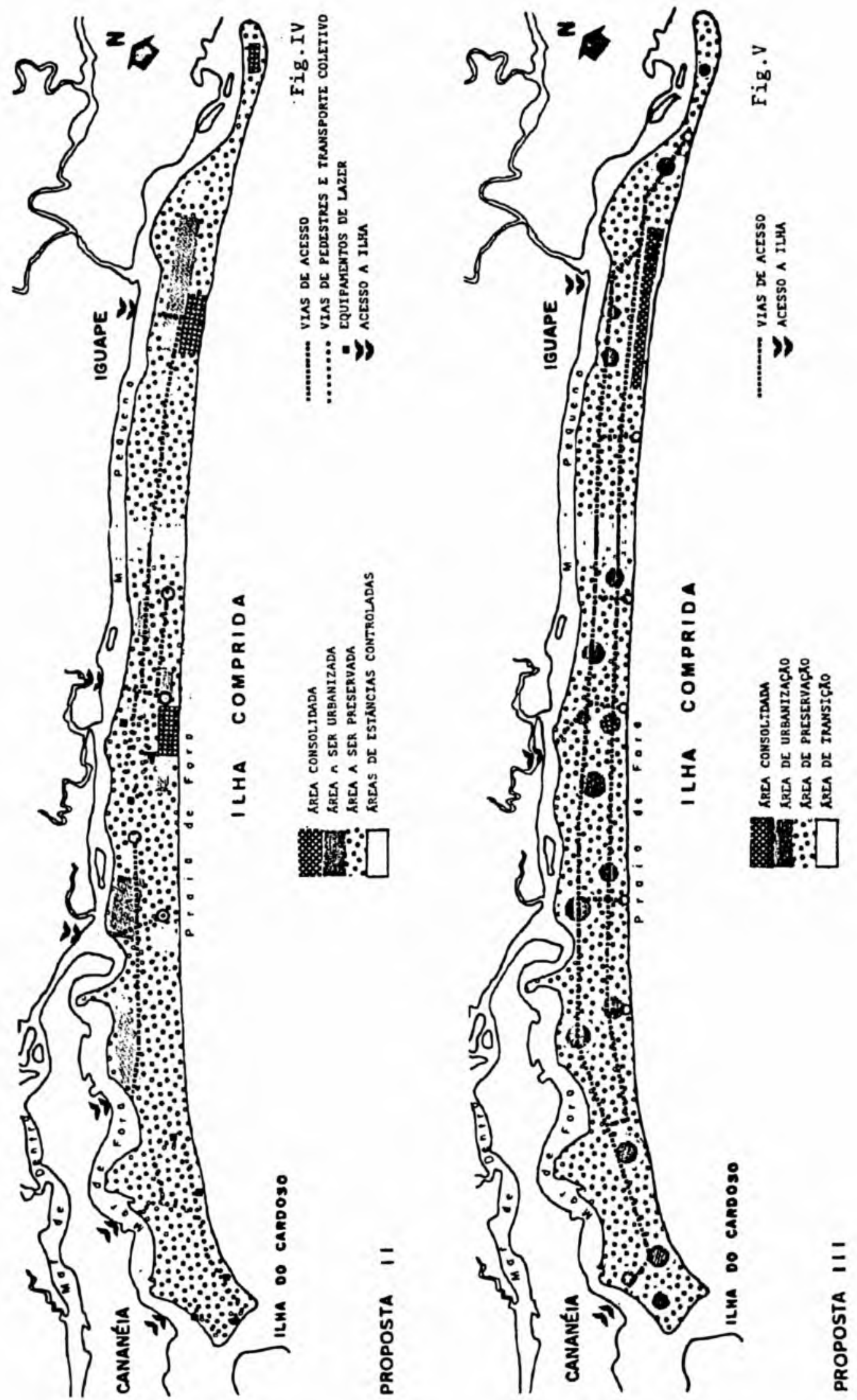


\section{BIBLIOGRAFIA}

AUSTIN, Richard. Designing the natural landscape. New York: Van Nostrand Reinhold, Co. 1984.

LYLE, John Tillman. Design for luman ecosystems: landscape, land use, and natural resources. New York: Van Nostrand Reinhold, 1985.

MARETTI, Claudio Carrera; FILET, Martinus. Illa Comprida: un desafio ao planejamento ambiental. In: Ambiente, v. 2, n. 2. p. 66-73. 1988.

MARSH, William. Environmental analysis: for land use and site planning. New York: McGraw Hill, 1978.

MEINIG, D. N. The Beholding Eye: ten versions of the same scene. Landscape Architecture, v. 66, n. $1,1976$.

Relatório CEPAUSP - Sorocotuba (Guarujá), Prainha (Peruíbe), Morro de Santa Terezinha (Santos), Paúba (São Sebastião).

ZUBE, Ervin H. et al. Landscape aesthetics and geography. In: Environmental Review, Fall, p. 31-55, 1988.

\section{REFERÊNCIAS ICONOGRÁFICAS}

IBGE - Carta do Brasil - Subaúma, Barra do Ribeira, Iguape, Ponta da Juréia, Pariquera-Açu, Ilha Anchieta, Caraguatatuba, Maresias, Ilha Grande, Santos, escala 1:50.000.

IGC Hipsometria do estado de São Paulo, 1982, escala 1:1.000.000.

IGC - Carta de utilização da terra do estado de São Paulo. Santos - Iguape - Cananéia - 1979, escala 1:250.000.

IGC Folha Topográfica de Iguape - 1954, escala 1:250.000.

SEMA Mapa n. 2 APA de Iguape - Cananéia, escala 1:250.000.

SEMA - Regularização da área de proteção aınbiental da Illha Comprida. Carta de Drenagem Interpretada, Carta Geológica-Geotécnica, Ecossistemas, Ocupação Urbana. 1989. escala $1: 25.000$.

Trabalho experimental desenvolvido em uın segınento do cursode especialização "Paisagismo: Planejamento e Projeto", promovido pela Faculdade de Arquitetura e Urbanismo da USP e a Fundação para a Pesquisa Ambiental, organizado pelo Grupo de Disciplinas Paisagem e Aunbiente do Departamento de Projelo da Faculdade de Arquitetura e Urbanisıno da Universidade de São Paulo.

Disciplinas: O Aunbiente na Paisagem Regional e Projeto Aunbiental.

Professores: Paulo Renato Mesquita Pellegrino e Silvio Soares Macedo (responsáveis).

Colaboradores: Profs. Martha Emerich, Eugênio Fernandes Queiroga, Helena Napoleon Degreas, Emmanuel Antonio dos Santos e Rosana M. da Rocha. 